\title{
O TRADUTOR COMO REDENTOR EM WALTER BENJAMIN
}

\author{
Michele Teixeira Passini \\ A tarefa do tradutor é redimir, na própria, a pura língua, exilada na \\ estrangeira, liberar a língua do cativeiro da obra por meio da recriação. \\ Walter Benjamin
}

\begin{abstract}
RESUMO
Com base no texto $A$ tarefa do tradutor, escrito por Walter Benjamin, buscamos no presente artigo compreender em que efetivamente consiste tal tarefa. Para tanto, discutimos a noção de pura língua e a partir dela, propomos pensar a tarefa do tradutor como agente da reconciliação das diferentes línguas, cujo trabalho coloca à mostra a familiaridade entre elas existente. Observamos que a reflexão benjaminiana, além de constituir-se como um elogio ao fazer tradutório, representa uma perspectiva original que rompe com concepções cristalizadas sobre tradução.
\end{abstract}

Palavras-chave: Tradução. Tradutor. Pura Língua. Walter Benjamin.

\section{THE TRANSLATOR AS A REDEEMER IN WALTER BENJAMIN}

\begin{abstract}
Based on the text "The task of the translator", written by Walter Benjamin, we aim at comprehending of what this task consists effectively. For this purpose, we discuss the notion of pure language and based on it, we propose to think the task of the translator as an agent of the reconciliation among languages, whose work provides visibility to the familiarity among them. We observe that the reflection about translation not only constitutes a compliment of the translation task, but also represents an original perspective, which ruptures with conceptions crystallized in this area.
\end{abstract}

Keywords: Translation; Translator; Pure language; Walter Benjamin. 


\section{Introdução}

Diminuindo fronteiras impostas pela multiplicidade linguística, a prática da tradução vem, desde muito tempo, ocupando lugar essencial na promoção do intercâmbio entre indivíduos geográfica e linguisticamente distantes. Contudo, embora sua importância prática seja inquestionável, grande é também sua contribuição de um ponto de vista teórico no campo dos estudos da linguagem, já que se desenvolve a partir de certos elementos essenciais, tais como língua, sujeito e produção de sentido, colocados em funcionamento numa complexa rede de relações, conforme ressalta o filósofo francês Henry Meschonnic em sua Poética do Traduzir. "Os problemas do traduzir põe a nu os efeitos do signo. É nisto que a tradução é ao mesmo tempo uma poética experimental e um lugar de observação único para a teoria da linguagem." (2010, LXIII)

Também de um ponto de observação que privilegia o aspecto teórico da tradução, a tripartição proposta por Frota (2000) é bastante elucidativa na apresentação de um panorama geral do quadro teórico das concepções acerca da tradução. A autora distingue três momentos distintos ancorando-se na concepção de língua que subjaz a cada um deles. Assim, elenca um primeiro momento cuja noção de língua é entendida como nomenclatura no período que designa por (1) prémoderno ou pré-estruturalista, seguido por um (2) momento estruturalista, cuja base encontra-se na noção saussuriana de langue, e, finalmente, um momento no qual a pretensa sistematicidade da língua passou a ser questionada por teóricos (3) pósestruturalistas. (FROTA, 2000, 42).

Apesar dessas teorizações que compõem o quadro dos estudos da tradução, é possível notar que grande parte da atenção dedicada às discussões acerca desse tema permanece majoritariamente voltada ao seu aspecto prático, o que pode resultar em um tratamento instrumental da tradução, no qual se privilegia seu produto em detrimento de seu processo.

É nesse ponto que o texto de Walter Benjamin intitulado A tarefa do tradutor nos parece bastante original, já que encaminha a discussão sobre tradução para outro escopo, explorando-a de um ponto de vista que nos parece sem precedentes nesta seara. Publicado originalmente em 1923, como prefácio de sua tradução dos poemas Tableaux Parisiens de Charles Baudelaire, nesse texto o autor se dedica a 
pensar a tradução da linguagem literária, entendendo que o compromisso do tradutor não é simplesmente com o leitor, pois, em se tratando de um texto de tal natureza, o que está em jogo não é a comunicação de um conteúdo, e é esse ponto que a distancia de um texto de outra natureza. Dito de outro modo, uma obra de arte, dado seu valor estético, não se presta meramente à comunicação, já que o que Ihe é de fato essencial não pode ser encerrado em um determinado conteúdo a ser transmitido.

De forma análoga, a tradução de uma obra literária não deve estar comprometida com a comunicação ao leitor do que disse o autor em outra língua, numa relação de mera equivalência entre termos. Para Benjamin a tarefa do tradutor vai muito além desse aspecto pragmático, na medida que tem por finalidade dotar de visibilidade o "mais íntimo relacionamento das línguas entre si". (BENJAMIN, 2011, 106). Assim, na contramão do famoso adágio traduttore, traditore, segundo o qual toda tradução causaria necessariamente uma perda quando comparada à leitura de um original, a reflexão benjaminiana sobre tradução constitui-se num verdadeiro elogio à tarefa de traduzir, pois é vista como um meio de restituir a afinidade perdida entre as línguas, e assim, reestabelecer a pretensa harmonia que reinava antes do marco babélico.

A fim de compreender em que consiste tal reconciliação pela tradução anunciada pelo filósofo, traçamos neste artigo um percurso que visa apresentar alguns pontos essenciais abordados pelo filósofo no ensaio no qual se dedica a pensar a tarefa do tradutor, amparando-nos, ainda na leitura que posteriormente realizou o filósofo Jacques Derrida em sua obra Torres de Babel. Para tanto, organizamos esta reflexão em duas grandes seções: na primeira discutimos a concepção de pura língua, central na compreensão do percurso que faz Walter Benjamin sobre a temática da tarefa do tradutor, para então, na segunda parte voltarmo-nos para a tarefa do tradutor propriamente dita. Ao final do percurso anunciado, pretendemos ter contribuído para desvelar em que consiste o fazer do tradutor pela ótica benjaminiana.

\section{A língua prometida: a noção de pura língua}


Assim como seu posicionamento a respeito da tradução distancia-se daqueles predominantes na área dos estudos da tradução, a concepção de língua que subjaz à reflexão de Walter Benjamin no referido ensaio também não coincide com aqueles presentes no cenário dos Estudos da Linguagem em geral. Trata-se do que poderia ser chamado de uma abordagem transcendente de língua, uma vez que se sustenta na premissa de que teria existido uma única e mesma língua compartilhada por todos, na qual a compreensão entre os homens não conheceria limites, permitindo que a comunicação entre os falantes fosse perfeita.

Desse modo, enquanto a Linguística tradicional, de base estruturalista, define a língua por suas relações diferenciais no interior de seu próprio sistema, resultando em um objeto sistematizável ${ }^{1}$, a proposta benjaminiana pauta-se numa língua abstrata e intangível, uma língua hipotética. De acordo com o episódio de Babel, narrado no Gênesis bíblico (11:1-9), frente à ousadia dos homens que desobedeceram às ordens recebidas, Deus os sentencia à confusão pela multiplicidade linguística, instaurando, desse modo, uma barreira entre eles marcada pela incompreensão. A multiplicidade das línguas é, vista por esse viés, um castigo que separa os homens e não lhes permite esquecer a impetuosidade divina para com aqueles que ousam descumprir sua vontade.

Desse modo, como afirma o autor, a pluralidade linguística escamoteia o fato de que as línguas possuem uma afinidade essencial, a qual não é relativa à família linguística ou às semelhanças no âmbito lexical das línguas, nem tampouco relaciona-se à familiaridade entre os diferentes textos. Esse ponto de afinidade entre as línguas só pode ser encontrado no que o autor denomina pura língua. Trata-se de um estado de língua plena e unívoca, por meio da qual todos poderiam compreender uns aos outros e expressar-se sem limitações, livre, portanto, de qualquer obscuridade.

O argumento defendido por Benjamin é o de que, tomadas isoladamente, as línguas são imperfeitas devido a sua incompletude. Uma língua representa uma determinada intenção, perceptível a partir da relação entre duas partes que lhe são constitutivas: o visado, e o modo de visar, conforme esclarece o autor: "o sentido

1 Concepção sustentada no Curso de Linguística Geral, de Ferdinand de Saussure. Conferir referências bibliográficas. 
não se esgota no visado, ele adquire essa significação precisamente pela maneira como o visado se liga, em cada palavra, ao modo de visar $(2011,109)$ ".

Se cada língua, com seu modo de visar específico, é incompleta, é somente na pura língua, resultante da harmonia de todos os modos de visar, que a completude poderia enfim ser encontrada. Em um texto intitulado Sobre a linguagem em geral e sobre a linguagem do homem, escrito em 1916, portanto cinco anos antes do texto em que se dedica à temática da tradução propriamente dita, Benjamin esclarece que embora toda manifestação do espírito faça parte da linguagem, a linguagem humana diferencia-se das demais pela sua capacidade de nomear. Assim, ao nomear os elementos da natureza, o homem aproxima-se de Deus: "A criação divina completa-se no momento em que as coisas recebem seu nome do homem, a partir de quem, no nome, somente a língua fala. (2011b, 56)"

Recorrendo, portanto, a uma concepção de língua transcendente, Benjamin remete-se ao estado paradisíaco, no qual haveria apenas uma língua cujo funcionamento é auto-referencial, e, portanto, sem uma função mediadora. Assim, as diferentes línguas carregam em si o peso da mediação, que é a razão pela qual a plurivocidade existe, e, com ela, a multiplicidade de sentidos que gera a confusão: "depois da queda, que, ao tornar a língua mediada lançou a base para a sua pluralidade, não era preciso mais que um passo para se chegar a confusão entre as línguas" (2011b, 69)

A relação entre o homem e o mundo, bem como dos homens entre si, desde então, jamais pôde acontecer de maneira direta, pois passou a ser sempre mediada pelos signos linguísticos. A linguagem perdeu sua transparência, tornando-se opaca e, desse modo, impedindo que a expressão exata da essência espiritual pudesse ser conhecida. Vemos, portanto, que a punição divina da pluralidade linguística não apenas deixou a mácula da incompreensão entre os homens, mas sobretudo provocou uma fissura na sua comunicação com o divino, cuja essência só pode ser acessada por meio da pura língua, ou seja, pela língua prometida.

Nesse contexto, a tradução torna-se um lugar privilegiado, pois permite não apenas observar pontos de proximidade e de distanciamento entre as diferentes línguas, mas principalmente porque constitui um meio de reconciliação, ainda que parcial, entre as línguas, e, assim, um passo em direção à pura língua. Em cada ato 
de tradução, portanto, o tradutor se depara com a incompletude tanto da língua da qual traduz, quanto daquela para a qual traduz. Nesse momento, ele está diante do efeito da plurivocidade, que se deixa ver no próprio movimento da tradução, mas ali está também a semente da pura língua que deve ser amadurecida pelo fazer do tradutor.

Assim, o que a tradução deflagra não é apenas a diferença entre as línguas, mas acima de tudo o caráter complementar que existe entre elas. É pela própria peculiaridade de cada uma delas, revelado por sua intenção, que juntas elas formam a tessitura de uma língua maior, que é a pura língua. A metáfora utilizada por Benjamin nos remete à imagem de um vaso fragmentado em inúmeros pedaços, no qual ao serem unidos, é precisamente a especificidade de cada uma de suas partes que assegura o todo. Em outras palavras, só é possível reconstituir o vaso a partir de seus fragmentos porque é precisamente nas diferenças que estão os lugares de encaixe. Essa metáfora nos parece bastante significativa para compreender 0 caráter complementar das línguas, ressaltado pela tradução, conforme podemos verificar nas palavras do autor:

\footnotetext{
Da mesma forma como os cacos de um vaso, para serem recompostos, devem encaixar-se uns aos outros nos mínimos detalhes, mas sem serem iguais, a tradução deve, ao invés de procurar dessemelhar-se ao sentido do original, conformar-se amorosamente, e nos mínimos detalhes, em sua própria língua, ao modo de visar do original, fazendo com que ambos sejam reconhecidos como fragmentos de uma língua maior, como cacos são fragmentos de um vaso. (p. 115. Grifo nosso)
}

Cada língua atua, portanto, como uma parte desse todo maior, que é a pura língua, na qual se fundem todos os modos de visar, permitindo que a plenitude se faça presente a medida em que o caráter de mediação da linguagem é desfeito. Ao postular que as línguas não são estranhas umas às outas, já que mantêm entre si um elo essencial, Benjamin está fazendo referência a essa complementaridade que as coloca como parte fundamental desse todo que representa a língua pura, anterior à punição divina.

Assim, o que ocorre em cada fazer tradutório, ao se aproximar uma língua da outra, é o crescimento de cada uma delas, conforme explica o filósofo francês Jacques Derrida (2002) ao abordar o caráter suplementar que resulta da tradução: 
Cada língua está como que atrofiada na sua solidão, magra, parada no seu crescimento, enferma. Graças à tradução, dito de outra forma, a essa suplementaridade linguística pela qual uma língua dá a outra o que lhe falta, e Iho dá harmoniosamente, esse cruzamento das línguas assegura o crescimento das línguas, e mesmo esse 'santo crescimento das línguas' 'até o termo messiânico da história'. Tudo isso se anuncia no processo tradutor, através da eterna 'sobrevida das obras' ou 'o renascimento infinito das línguas'. Essa perpétua revivescência, essa regeneração constante pela tradução, é menos uma revelação, a revelação ela mesma, que uma anunciação, uma aliança, uma promessa. (DERRIDA, 2002, 68)

Como vemos nas palavras de Derrida, desse ponto de vista a tradução é vista como uma atividade messiânica, pois muito mais que estabelecer relações de equivalência entre duas línguas distintas, ela aproxima duas línguas incompletas e opacas e, assim fazendo, anuncia a boa nova da língua prometida.

\section{O tradutor como agente da "desbabelização"}

Passamos agora à discussão acerca da tarefa do tradutor propriamente dita. Considerando a noção de pura língua que norteia a reflexão benjaminiana, entendida como uma língua unívoca, da qual só temos suposições, convém questionar o que pode o sujeito incumbido da tarefa de traduzir nesse espaço intermediário entre duas línguas incompletas, com intenções próprias. De uma língua a outra, ao tradutor cabe muito mais que cumprir um jogo de equivalências ou adaptações, pois seu fazer está relacionado, em última instância, com o encontro da pura língua.

Para Derrida (2002), já no próprio título do prefácio de Benjamin - A tarefa do tradutor - é possível encontramos a ênfase dada pelo autor ao trabalho daquele que toma a frente de desfazer o efeito babélico. O termo "tarefa" nos leva, atentando para possíveis relações parafrásticas, a um sentido de um engajamento e até mesmo uma missão. Em que exatamente estaria o tradutor engajado? Espera-se do tradutor, conforme o autor recém citado, a restituição da dívida de que a tradução não permite esquecer. "Ele [Benjamin] nomeia o sujeito da tradução como sujeito endividado, obrigado por um dever, já em situação de herdeiro, inscrito como sobrevivente dentro de uma genealogia, como sobrevivente ou agente da sobrevida" (DERRIDA, 2002, 33)

Trata-se, portanto, na esteira da afirmação recém apresentada, de assumir uma dívida, a qual por mais que tente, jamais poderá ser paga. É nesse sentido que 
Derrida refere-se à tradução como necessária e impossível; necessária na medida que toda a dívida pressupõe um compromisso, e impossível porque o acesso à completude da univocidade linguística é, desde a imposição da pena divina que tornou a língua mediada, interdita.

A tarefa do tradutor é única, e de forma alguma coincide com a do autor, pois, enquanto a intenção do último é classificada por Benjamin como ingênua, primeira e intuitiva, a do primeiro é considerada derivada, última e ideativa. Eis aqui outro ponto de ruptura com grande parte das concepções que sustentam os dizeres sobre tradução: ao distinguir os papeis do tradutor e do autor, Benjamin promove um deslocamento na constante comparação que se costuma fazer entre o texto traduzido e o original, como se um precisasse ser a imagem especular do outro. O tradutor deixa, portanto, de ser visto como um usurpador da posição autoral, pois a ele cabe um papel absolutamente distinto, que em Benjamin tem a ver com a integração da diferença entre línguas. Desse modo, para esse autor o maior elogio que se pode tecer a uma tradução não reside na possibilidade que ela seja lida como se fosse o original, mas sim, que ela consiga expressar esse anseio por uma complementação entre as línguas.

Além disso, Benjamin ressalta, ainda, a capacidade que o trabalho do tradutor possui de prolongar a existência do original. Trata-se do papel da tradução como condição do que o autor designa por pervivência da obra original. Sendo posterior ao original, uma tradução é sempre uma maneira de assegurar a permanência da vida da obra. Essa vida, ressalta o autor, não é estática, na medida em que se refere aos movimentos que promove na história. Assim, a pervivência do original, resultante de sua tradução, não apenas o coloca novamente em vida, mas também o renova e transforma. A esse respeito, Derrida completa que: "Se o tradutor não restitui nem copia um original, é que este sobrevive e se transforma. A tradução será na verdade um momento de seu próprio crescimento, ele aí completar-se-á engrandecendo-se." (DERRIDA, 2002, 46)

No que tange à tarefa do tradutor propriamente dita, portanto, Benjamin novamente distancia-se das teorizações realizadas na seara dos estudos da linguagem. É precisamente pela compreensão da noção de pura língua, tal qual foi proposta pelo autor, que o papel do tradutor adquire tamanha importância. Em seu 
fazer tradutório é que reside a restituição da familiaridade entre as línguas, a qual atesta que elas são partes de um todo maior, que é essa língua prometida. Messiânica, como nos diz Derrida, é a tarefa do tradutor. Não mais usurpador do lugar do autor, o tradutor para Benjamin está livre para cumprir a missão que lhe cabe, qual seja, a de redimir a língua presa na obra, conforme lemos nas palavras do autor que ocupam a epígrafe deste trabalho.

\section{Considerações}

Como mencionamos no início deste artigo, há um espaço nos Estudos da Linguagem que reclama que se pense com mais atenção a tradução por um viés teórico, dada sua importância como processo linguageiro complexo, envolvendo uma trama de noções teóricas fundamentais. Neste artigo, em que partimos das conceituações benjaminianas sobre tradução, bem como de comentários tecidos por Jacques Derrida, procuramos desvelar em que consistia a tarefa do tradutor. Para tanto, abordamos a concepção de língua na qual se ancora Walter Benjamin, à qual nos referimos como sendo de ordem transcendental, na medida que sugere uma língua hipotética, justificada a partir de textos bíblicos. Vimos que a noção de pura língua, entendida como um estado de língua que por sua auto-referencialidade assegura a comunicação plena, produz efeitos na maneira de conceber o papel do tradutor.

Tendo em vista que a derradeira sanção divina resultou na multiplicidade linguística, fadando os homens a não mais se compreenderem, é na tarefa do tradutor que encontramos a possibilidade de reverter, ainda que de forma parcial, os efeitos desse castigo. Cada língua, imperfeita em sua solidão, torna-se mais rica ao aproximar-se da outra por ocasião do trabalho do tradutor, em sua tarefa de deixar à mostra o elo constitutivo que possuem. Redentor dos efeitos babélicos, é o tradutor em sua tarefa que conseguirá restituir aos homens algo de divino que foi perdido.

Assim, é possível defender que o trabalho de Benjamin se constitui como um elogio à tradução e à tarefa do tradutor, na medida que o entende como uma um passo em direção à completude, encerrada na pura língua. Além disso, é importante observar certas rupturas quea reflexão do autor promove com concepções já cristalizadas sobre tradução, tais como a soberania da figura autoral em detrimento 
do papel do tradutor, ou ainda, a singularidade do texto traduzido que não mais compete com o original, pois o faz perviver transformado e renovado pela nobre tarefa do tradutor. 


\section{REFERÊNCIAS}

BENJAMIN, Walter. A tarefa do tradutor. In: Escritos sobre mito e linguagem. Tradução de Susana Kampff e Ernani Chaves. São Paulo: Duas Cidades; Editora 34, 2011.

Sobre a linguagem em geral e sobre a linguagem do homem. In: Escritos sobre mito e linguagem. Tradução de Susana Kampff e Ernani Chaves. São Paulo: Duas Cidades; Editora 34, 2011 b.

DERRIDA, Jacques. Torres de Babel. Tradução de Junia Barreto. Belo Horizonte: Editora UFMG, 2002.

FROTA, Maria Paula. A singularidade na escrita tradutora: linguagem e subjetividade nos estudos da tradução, na linguística e na psicanálise. Campinas, SP: Pontes, 2000.

MESCHONNIC, Henry. Poética do traduzir. Tradução de Jerusa Pires Ferreira e Suely Fenerich. São Paulo: Perspectiva, 2010.

SAUSSURE, Ferdinand. Curso de Linguística Geral. Tradução de Antônio Chelini, José Paulo Paes, Izidoro Blinkstein. São Paulo: Cultrix, 2006. 